\section{CONSTITUTION AND HEALTH}

By Raymond Pearl. (Psyche Miniatures General Series). Kegan Paul. Price 2/6d.

The title of this volume and the name of the author are a guarantee of its importance to the medical man. It is a discussion of general principles, an exposure of the complexity of the problem and a demonstration of the great caution required in drawing conclusions from experimental work in this field.

The author points out how the so-called constitution is not, as is too often surmised, merely a matter of inheritance, but that it is influenced by environment as well, and is withal so complex in its nature that it is beyond our powers at the present moment to analyse or measure. He concludes that we are just at the beginning of some understanding of a highly complicated but undoubtedly important matter, but as he says, "Little if anything in the way of general principles, soundly grounded and of established validity, has yet emerged"'. These views he illustrates by a personal study of the health history of a series of women classified according to body form. He shows, however, the lines along which the medical man may prosecute research in the accumulation of data (the necessary spadework as he calls it) and thus help in the elucidation of the question. For this reason alone we would commend the volume to the notice of our readers.

\section{THE POCKET ANATOMY}

By C. H. FAGGe. (9th edition). Balliere, Tindall \& Cox. Price 5/-.

All students of medicine will welcome the new edition of this well-known vade mecum which has been a stand-by to nearly three generations of undergraduates. The present edition is on the same lines as its predecessors but possesses one outstanding feature in that it incorporates the English terminology recently approved by the Anatomical Society of Great Britain and Ireland. At the same time the author has taken advantage of the opportunity to include recent advances in our knowledge of the central and autonomic nervous systems.

\section{INFANTILISM}

By E. Apert. Translated by R. W. B. Ellis, M.D. Martin Hopkins, Ltd., London. 1933. 117 pp. Price 7/6 net.

The subject of infantilism is bound to be one of considerable difficulty, for so long as our knowledge of the factors which control or modify growth and development remains as fragmentary as it is to-day, it must necessarily prove impossible to write comprehensively on this subject, and the views of one individual are not likely to prove entirely acceptable to others. Dr. Apert has studied the subject for many years, and uses the word infantilism in a wide sense. He includes under this head conditions ranging from progeria and cœliac infantilism to pituitary gigantism with sexual infantilism, though inclined to exclude "so-called cardiac infantilism". Many will read his conclusions with interest. He makes statements, however, likely to challenge criticism in this country; for example, he holds that "when the retardation is regular and the patient, having reached adult years, still has all the appearance of an adolescent before puberty or of a young child in normal health, this simple and uniform infantilism suggests thyroid dysfunction", and he classifies Still's disease as a type of "splenic infantilism". The translator's work has been carried through admirably.

\section{DIABETES : Reasons and Recipes}

By Dr. E. E. Claxton and Miss Lucy Burdekin. The Bodley Head. Price 5/-.

As a diabetic is in all probability a diabetic for the rest of his life and the duration and comfort of his existence depend on the care he exercises over his food, it is of the utmost importance that he understands the reasons for dietetic restrictions. The explanation of the disease, the rationale of the necessary treatment, the method of carrying this out and the good results to be obtained by efficient co-operation with his doctor are all set forth in the above volume in language that the patient himself can understand. One impontant feature of the volume is the large collection of recipes for making a variety of suitable dishes, the tables giving the carbohydrate content of different foodstuffs and the list of sample menus for different classes of patient. 